\title{
Isolation of Syncytial Microvillous Membrane Vesicles From Human Term Placenta and Their Application in Drug-Nutrient Interaction Studies
}

\author{
Eric M. van der Aa, Jenny H. J. Copius Peereboom-Stegeman, and Frans G. M. Russel \\ Departments of Pharmacology (E.M.A. and F.G.M.) and Toxicology (J.H.J.C.P.S.), University of Nijmegen, \\ Nijmegen, The Netherlands
}

\begin{abstract}
The initial step in placental uptake of nutrients occurs across the syncytial microvillous membrane of the trophoblast. This study was designed to isolate syncytial microvillous membrane vesicles (SMMV) of human term placenta, to validate their purity and viability, and to investigate the interaction of several commonly used drugs with the transport of two essential nutrients: alanine and choline. SMMV were isolated according to an established procedure, but instead of homogenization the initial preparation step was replaced by mincing of placental tissue followed by gently stirring to loosen the microvilli. These modifications doubled the protein recovery and increased the enrichment in alkaline phosphatase, whereas no substantial contamination with basal membranes nor interfering subcellular organelles was found. The functional viability of the vesicles was evaluated through the transport of alanine. In accordance with literature, uptake was sodium-dependent, inhibitable by structural analogues, and saturable. A number of cationic drugs were able to inhibit choline uptake, whereas no effect on alanine transport was observed. Anionic drugs, drugs of abuse, and catecholamines did not interfere with alanine transport either. In conclusion, our isolated SMMV provide a suitable tool for screening drug-nutrient interactions at the level of membrane transport. In view of the very low susceptibility of the alanine transporter to drug inhibition and the relatively high drug concentrations necessary to inhibit choline transport, it seems unlikely that clinically important drug interactions may occur with these nutrients.
\end{abstract}

Key Words: Human term placenta; Syncytial microvillous membrane vesicles; Drug-nutrient interaction

\section{Introduction}

In the human hemochorial placenta, the trophoblast forms a true syncytium without intercellular spaces. This polarized epithelium separates maternal and fetal circulation by means of the syncytial microvillous membrane (SMM) facing the matcrnal circulation and the basal membrane (BM) facing the fetal circulation. Fetal supply of nutrients and excretion of waste products across the placenta is mediated by these membranes forming, together with a core of connective tissue, the functional unit of the human placenta, called chorionic villus or cotyledon (Page, 1993).

Address reprint requests to Dr. Eric M. van der Aa, Department of Pharmacology, Faculty of Medical Sciences, University of Nijmegen, P.O. Box 9101, 6500 HB Nijmegen, The Netherlands.

Received October 1994; revised and accepted January 1995.
During the past 20 years several procedures have been described for the isolation of membranes from human term placenta. Isolation of SMM was introduced by Smith et al. (1974), who separated microvilli from their syncytiotrophoblastic surface by isotonic agitation. Nowadays, widely used modifications of this method involve homogenization or mincing of placental tissue followed by differential centrifugation, with (Booth et al., 1980; Glazier et al., 1988; Illsley et al., et al., 1990) or without (Boyd and Lund, 1981) $\mathrm{Mg}^{2+}$-aggregation of nonmicrovillous membranes. Isolation procedures for syncytial basal membranes (BM), however, are less often described. The main reason for this is the poor accessibility of these membranes in the syncytial structure of the trophoblast. A method relatively often referred to in literature involves sonication, hypotonic lysis and EDTA incubation to detach separate membranes from the 
connective tissue, followed by discontinuous Ficol-gradient centrifugation (Kelley et al., 1983) or differential centrifugation (Hoeltzli et al., 1990). Membrane vesicles are a preeminent tool to investigate mechanisms of transport and drug interactions on nutrient transporters, independently of other cell types or placental metabolism.

Fetal growth depends highly on placental transport of nutrients from the maternal to the fetal circulation. The initial step in placental transfer involves active uptake across the SMM into the trophoblast. The neutral amino acid alanine is the most abundant amino acid in maternal circulation (Philipps et al., 1978) and essential for fetal protein synthesis or as energy source for placental or fetal metabolism. The quaternary ammonium compound choline must be transported from maternal circulation into the trophoblast, because the placenta is unable to synthesize choline (Welsch, 1978). Obviously, interaction with the transfer of these nutrients may impair fetal growth.

Transfer of alanine across the SMM occurs predominantly via the sodium-dependent system A. The system is responsible for the accumulation of alanine from the maternal circulation into the trophoblast. The gradient established enables (facilitated) diffusion of this amino acid into the fetal circulation, resulting in a higher fetal than maternal alanine concentration (Yudilevich and Sweiry, 1985). Because several drugs, like ouabain and digoxin, can interfere with $\mathrm{Na}^{+} / \mathrm{K}^{+}$ATP-ase, an enzyme essential for maintaining the transmembrane sodiumgradient, an inhibitory effect on alanine transport can be assumed (Kihlstrom and Kihlstrom, 1981). Drugs may also interact directly with the human placental alanine transporter, as was shown by Dicke et al. (1993) for $\mathrm{S}(-)$ cocaine in human microvillous membrane vesicles. Barnwell and Rama Sastry (1983) found reduced active uptake of the system A-dependent amino acid AIB in the presence of high concentrations of cocaine, nicotine, or morphine in human placental villi, but the type of inhibition could not be attributed to competition with the amino acid at the transport site. In a human cotyledon perfusion system, transfer of AIB was not impaired by ethanol (Schenker et al., 1989a) or nicotine and a combination of nicotine and ethanol (Schenker et al., 1989b). Furthermore, acetaldehyde did not inhibit sodium-dependent alanine uptake into SMMV (Asai et al., 1984). Acetylsalicylic acid has been shown to inhibit alanine transfer into the trophoblast in a guinea pig placenta perfusion system, but this was assumed to be an indirect effect, due to an influence on the uterus muscle bypass flow (Rybakowski et al., 1993). The metabolic inhibitors dinitrophenol and iodoacetate did reduce alanine transfer in sheep placenta (Sepulveda and Wooding, 1984). The local anesthetic lidocaine and the anticholinergics scopolamine and atropine did interact with AIB uptake in a nonspecific nature (Fant and Harbison, 1981). Inhibitors of choline-acetyltransferase were able to inhibit AIB uptake in placental villi. These results suggest that neutral amino acid transport is linked to the cholinergic system (Rowell and Rama Sastry, 1981).

The mechanisms of placental transport of choline, a precursor in the cholinergic system, and phospholipid synthesis were recently investigated in our laboratory. Uptake into SMMV was found to be membrane potential-dependent and saturable with a $\mathrm{K}_{\mathrm{m}}$ of $550 \mu \mathrm{mol} / \mathrm{L}$ (van der Aa et al., 1994b).

Hardly any information is available on the mechanisms of drug interactions with nutrient transporters. We designed this study to isolate SMMV, validate their functional viability, and investigate the potential of various commonly used drugs to interact with membrane transport of alanine and choline.

\section{Materials and Methods}

\section{Isolation of Membrane Vesicles}

SMMV were isolated essentially according to Method 3 as described by Glazier, Jones, and Sibley (1988), based on the method reported by Booth and Kenney (1974) for rabbit kidney brush-border membrane vesicles. However, we introduced some modifications in order to improve the isolation performance.

Human term placentas from uncomplicated pregnancies were obtained within 15 min after vaginal or ceasarian delivery and brought into $0.9 \% \mathrm{NaCl}\left(4^{\circ} \mathrm{C}\right)$. All subsequent steps were performed at $4^{\circ} \mathrm{C}$. After removing the cord, amniochorion, and decidua, placental tissue was cut from the maternal side and washed three times in $0.9 \% \mathrm{NaCl}$. The tissue was minced in a Waring blender in 300-mmol Mannitol per liter, 10-mmol Hepes-Tris per liter, $\mathrm{pH}=7.4$, and 1 -mmol $\mathrm{MgSO}_{4}$ per liter (MHT buffer). The mince was stirred for $30 \mathrm{~min}$ to loosen the microvilli and filtered through four layers of woven cotton gauze. A sample of this starting mince was taken for enzyme analysis. $\mathrm{MgCl}_{2}$ was added to the filtrate to a final concentration of $10 \mathrm{mmol} / \mathrm{L}$, and the filtrate was stirred for $15 \mathrm{~min}$. It was centrifuged at $2200 \mathrm{~g}$ for $10 \mathrm{~min}$ in an Heraeus sepatech Minifuge RF (Kalkberg, Germany). The pellet was discarded, and the supernatant was centrifuged at $23,500 \mathrm{~g}$ for $40 \mathrm{~min}$ in a IEC B-60 ultracentrifuge (Daiment Div., Needham, MA). G-forces were directed to the bottom of the tube. The pellet from this run was suspended in MHT buffer with a $19-\mathrm{Ga}$ and $25-\mathrm{Ga}$ syringe needle ( 5 strokes). This homogenate was again exposed to $10-\mathrm{mmol} \mathrm{MgCl}_{2}$ per liter. After repeated differential centrifugation, syncytial microvillous membrane vesicles were obtained and suspended with a $25-\mathrm{Ga}$ syringe needle (10 strokes) in a 
desired intravesicular buffer, frozen in liquid nitrogen, and stored at $-80^{\circ} \mathrm{C}$ for 4 weeks at the maximum.

$\mathrm{BMV}$ were isolated from human term placenta according to Hoeltzli et al. (1990) for comparison of the $\mathrm{Ca}^{2+}$ uptake characteristics into SMMV and BMV. Briefly, tissue was minced in a Waring blender and sonicated for $10 \mathrm{sec}$ in portions of $30 \mathrm{~g} / 100 \mathrm{~mL} 50-\mathrm{mmol}$ Tris- $\mathrm{HCl}$ buffer per liter, $\mathrm{pH}=7.4$. Subsequently, to free basal membranes from connective tissue, the mince was incubated for $30 \mathrm{~min}$ in hypotonic $5-\mathrm{mmol}$ Tris- $\mathrm{HCl}$ buffer per liter, $\mathrm{pH}=7.4$, followed by incubation for 30 $\mathrm{min}$ at room temperature (all other steps were performed at $4^{\circ} \mathrm{C}$ ) in 50-mmol Tris- $\mathrm{HCl}$ per liter, 250mmol sucrose per liter, and 10-mmol EDTA buffer per liter, $\mathrm{pH}=7.4$, and resonication for $20 \mathrm{sec}$. Basal membranes were purified by $\mathrm{Mg}^{2+}$-aggregation and differential centrifugation, frozen in liquid nitrogen, and stored at $-80^{\circ} \mathrm{C}$.

\section{Analytical Methods}

The activity of marker enzymes was analyzed according to previously described methods in $\mathrm{M}_{0}$ and SMMV: alkaline phosphatase for SMM (Mircheff and Wright, 1976), $\mathrm{Na}^{+} / \mathrm{K}^{+}$ATP-ase for BM (Schoot et al., 1977), succinate dehydrogenase for mitochondria (Pennington, 1961), and NADPH cytochrome-C-reductase for smooth endoplasmatic reticulum (Omura and Takesue, 1970). Protein was assayed with a coomassie blue kit (Biorad, Munich, Germany) with bovine serum albumin as standard.

Uptake of $\left[{ }^{3} \mathrm{H}\right]$-alanine and $\left[{ }^{3} \mathrm{H}\right]$-choline into SMMV was measured in quadruplicate at room temperature using a rapid filtration technique (Russel et al., 1988) by the addition of $10-$ or $5-\mu \mathrm{L}$ (approximately $8-4-\mu \mathrm{g}$ protein) vesicles to $40-$ or $195-\mu \mathrm{L}$ extravesicular medium containing a tracer amount of radiolabeled solute, respectively. Uptake of ${ }^{45} \mathrm{CaCl}_{2}$ into $\mathrm{SMMV}$ was determined according to van Heeswijk et al. (1984). Uptake was started by the addition of $10-\mu \mathrm{L}$ vesicles $(7-10 \mu \mathrm{g})$ to $90-\mu \mathrm{L}$ extravesicular medium, containing $0.5-\mathrm{mmol}$ $\mathrm{CaCl}_{2}$, EGTA, NTA, and HEDTA per liter with 5.13mmol $\mathrm{MgCl}_{2}$ per liter, and 3-mmol ATP per liter to obtain 1- $\mu$ mol free $\mathrm{Ca}^{2+}$ per liter and $1.5-\mathrm{mmol} \mathrm{Mg}^{2+}$ per liter in the presence of ATP, and $2.3-\mathrm{mmol} \mathrm{MgCl}_{2}$ per liter to obtain $1-\mu$ mol free $\mathrm{Ca}^{2+}$ per liter and $1.5-\mathrm{mmol} \mathrm{Mg}^{2+}$ per liter in the absence of ATP, all containing a tracer amount of ${ }^{45} \mathrm{Ca}^{2+}$ and adjusted to 310 mosmol with $100-\mathrm{mmol} \mathrm{KCl}$ per liter and mannitol. For the calculations the dissociation constants between EGTA, NTA, HEDTA, $\mathrm{Ca}^{2+}$, and $\mathrm{Mg}^{2+}$ were used according to Ghijsen et al. (1982) with the computer program proposed by van Heeswijk et al. (1984). At appropriate time intervals, the reaction was stopped by adding 2-mL ice-cold intravesicular buffer or, in case of
$\mathrm{Ca}^{2+}$ uptake studies, 1-mL ice-cold intravesicular buffer to which $0.1-\mathrm{mmol} \mathrm{LaCl}_{3}$ per liter was added to remove extravesicular bound $\mathrm{Ca}^{2+}$. The diluted samples of the alanine and choline uptake studies were filtered under vacuum through a glass fibre filter (Whatman $\mathrm{GF} / \mathrm{F}$ ) and, in case of the $\mathrm{Ca}^{2+}$ uptake studies, $900 \mu \mathrm{L}$ of the diluted samples through a presoaked acetate/nitrate filter (Schleicher \& Schull ME25). The filters were washed twice, and the radioactivity remaining on the filters was counted in a Beckman LS $6000 \mathrm{LL}$ liquid scintillation counter. Corrections were made for aspecific filter binding. Uptakes are expressed as nmol or $\mathrm{pmol} / \mathrm{mg}$ protein or as percentage of control uptake (mean $\pm \mathrm{SD}$ or SE, with $n$ representing amount of experiments with different vesicle preparations). Transport conditions and control uptake in $\mathrm{pmol} / \mathrm{mg}$ protein are given in the legends.

For electron microscopy, the membrane suspension was centrifuged at $1500 \mathrm{~g}$ for $10 \mathrm{~min}$. Pellets were fixed in $2 \%$ glutardialdehyde in 0.1-mol phosphate buffer per liter, $\mathrm{pH}=7.4$ for $5 \mathrm{hr}$, washed and suspended in $2 \%$ agar $\left(60^{\circ} \mathrm{C}\right)$. The cured (at $4^{\circ} \mathrm{C}$ for $\left.30 \mathrm{~min}\right)$ agar was cut into small pieces, fixed in $2 \%$ glutardialdehyde, washed and post-fixed in $1.5 \%$ osmiumtetroxide in $0.1-\mathrm{mol}$ phosphate buffer per liter. The blocks were washed and dehydrated in a series of graded alcohols. The dehydrated blocks were embedded in epon. Ultrathin sections were cut on a Reichert microtome (Vienna, Austria) and mounted on a 150-mesh uncoated copper grid. The sections were contrasted with $3.36 \%$ uranylacetate with lead citrate and examined in a Philips 300 transmission electron microscope (Eindhoven, The Netherlands) at $60 \mathrm{kV}$.

\section{Chemicals and Materials}

$\left[{ }^{3} \mathrm{H}\right]$-L-alanine $(77 \mathrm{Ci} / \mathrm{mmol})$ was obtained from New England Nuclear (Dreieich, Germany). ${ }^{45} \mathrm{CaCl}_{2} \quad(17$ $\mathrm{mCi} / \mathrm{mg})$ and $\left[{ }^{3} \mathrm{H}\right]$-choline $(83 \mathrm{Ci} / \mathrm{mmol})$ were obtained from Amersham (Buckinghamshire, United Kingdom). $\mathrm{S}(+)$ - and $\mathrm{S}(-)$ adrenaline were purchased from Sterling-Winthrop Research Institute (New York, NY), S(+/ -)cocaine from Genfarma (Maarssen, The Netherlands), and S(-)nicotine from Janssen Chimica (Beerse, Belgium). All other chemicals were purchased from either Sigma (St. Louis, MO), Merck (Darmstadt, Germany) or Boehringer Mannheim (Mannheim, Germany) and were of analytical grade. GF/F filters were obtained from Whatman Int. Ltd. (Maidstone, United Kindgom) and ME25 filters from Schleicher \& Schüll (Dassel, Germany).

\section{Data Analysis}

Paired Student's $t$-test was used to determine statistical significance $(p<.05)$. Curve fitting was done by 
least-squares nonlinear regression analysis using the computer program PCNONLIN (Metzler and Weiner, 1989).

\section{Results}

\section{Isolation Characteristics}

Marker enzyme analysis revealed a 21 -fold enrichment in alkaline phosphatase for SMMV. Addition of $0.1 \%$ saponin, triton $\mathrm{X}-100$, or sodium-deoxycholate to SMMV prior to incubation increased alkaline phosphatase slightly, showing that approximately $90 \%$ of the vesicles were orientated right-side out, as is common for SMMV (Glazier et al., 1988). $\mathrm{Na}^{+} / \mathrm{K}^{+}$ATP-ase activity was nearly fivefold enriched. The SMMV preparation was not, or to a very small extent, enriched in succinate dehydrogenase and NADPH-cytochrome-C-reductase. Protein yield and specific activities and enrichment factors of the different marker enzymes are given in Table 1. Electron micrographs of the SMMV preparation are shown in Figure 1.

\section{$\mathrm{Ca}^{2+}$ and Alanine Uptake}

${ }^{45} \mathrm{Ca}^{2+}$ uptake into SMMV, as shown in Figure 2, was slightly stimulated by ATP, and addition of A23187 did not result in $\mathrm{Ca}^{2+}$ release, indicating that $\mathrm{Ca}^{2+}$ was not accumulated into the vesicles. The inset curve shows ATP-dependent intravesicular accumulation of free $\mathrm{Ca}^{2+}$ into BMV, releasable with A23187.

Time-dependent uptake of $100-\mu \mathrm{mol}\left[{ }^{3} \mathrm{H}\right]$-alanine per liter into SMMV is shown in Figure 3. An overshoot above equilibrium (peak vs equilibrium at $30 \mathrm{sec}=1.5$ ) was seen in the presence of an inwardly directed $\mathrm{Na}^{+}$gradient, providing evidence for sodium-dependent up-

Table 1. Protein Recovery and Specific Activities of Marker Enzymes

\begin{tabular}{|c|c|c|c|c|c|}
\hline & $\begin{array}{l}\text { Starting } \\
\text { mince }\end{array}$ & SMMV & $\begin{array}{l}\text { Enrichment } \\
\text { factor }\end{array}$ & $\begin{array}{l}\text { Yield } \\
(\%)\end{array}$ & $n$ \\
\hline Protein & $32 \pm 8$ & $0.4 \pm 0.1$ & & $1.2 \perp 0.3$ & 21 \\
\hline $\begin{array}{l}\text { Alkaline } \\
\text { phosphatase }\end{array}$ & $52 \pm 16$ & $1080 \pm 390$ & $21 \pm 5$ & & 21 \\
\hline+ saponin $(0.1 \%)$ & & $1210 \pm 190$ & & & \\
\hline $\begin{array}{l}+ \text { triton } X-100 \\
\quad(0.1 \%)\end{array}$ & & $1250 \pm 380$ & & & 3 \\
\hline $\begin{array}{l}+ \text { deoxycholate } \\
(0.1 \%)\end{array}$ & & $1210 \pm 340$ & & & 3 \\
\hline $\mathrm{Na}^{+} / \mathrm{K}^{+}$Al'P-ase & $0.60 \pm 0.02$ & $3.0 \pm 1.6$ & $4.9 \pm 4.3$ & & \\
\hline $\begin{array}{l}\text { Succinate } \\
\text { dehydrogenase }\end{array}$ & $3.2 \pm 0.7$ & $2.9 \pm 0.7$ & $0.90 \pm 0.08$ & & \\
\hline $\begin{array}{l}\text { Cytochrome-C- } \\
\text { reductase }\end{array}$ & $4.6 \pm 1.2$ & $6.6 \pm 2.5$ & $1.4 \pm 0.8$ & & 6 \\
\hline
\end{tabular}

Data are presented as $\mathrm{mg}$ protein/g placenta wet weight for protein or $\mu \mathrm{mol} / \mathrm{h} / \mathrm{mg}$ protein for marker enzymes (means $\pm \mathrm{SD}$ ). take against a concentration gradient. By permeabilizing SMMV in the presence of $0.1 \%$ saponin, uptake at 60 min (equilibrium) was reduced to approximately $20 \%$ of uptake without saponin, indicating intravesicular accumulation rather than nonspecific membrane binding. The existence of mediated transport for alanine in SMMV was further evaluated by determining the concentration-dependent alanine uptake in the presence or absence of an inwardly directed $\mathrm{Na}^{+}$-gradient, which is shown in Figure 4. The curve resulting from subtraction of the sodium-independent component $\left(50-\mathrm{mmol} \mathrm{K}^{+}\right.$gradient per liter) from the total uptake $(50-\mathrm{mmol}$ $\mathrm{Na}^{+}$-gradient per liter) shows saturability and could be described according to Michaelis-Menten kinetics. Nonlinear regression analysis revealed a $\mathrm{K}_{\mathrm{m}}$ of $0.23 \pm 0.07$ $\mathrm{mmol} / \mathrm{L}$ and $\mathrm{a} \mathrm{V}_{\max }$ of $359 \pm 22 \mathrm{pmol} / \mathrm{mg}$ per $15 \mathrm{sec}$ for sodium-dependent alanine uptake.

\section{Interaction with Alanine and Choline Transport}

Uptake at $15 \mathrm{sec}$ of $100-\mu \mathrm{mol}\left[{ }^{3} \mathrm{H}\right]$-alanine per liter in the presence of an inwardly directed sodium gradient into SMMV was inhibited by $35 \%$ in the presence of 5 -mmol glycine per liter and by $52 \%$ in the presence of 5 -mmol phenylalanine per liter as shown in Table 2 . Uptakes at 1 min showed no overshoot, and equilibrium uptake at $60 \mathrm{~min}$ in the presence of these amino acids was not affected. These results further confirmed the presence of mediated alanine transport and showed that interactions with active alanine transport can be demonstrated in our vesicles without an influence on vesicle volume.

The effect of several drugs on alanine uptake is shown in Table 3. None of the drugs were able to inhibit alanine uptake significantly, except for indomethacin. Because uptake at $60 \mathrm{~min}$ (equilibrium) was also reduced to $60 \%$ of control uptake, it is difficult to ascribe this inhibition to a direct effect on the alanine transporter. In the presence of all other inhibitors, peak uptake at $60 \mathrm{sec}$ and equilibrium uptake at $60 \mathrm{~min}$ was not altered (data not shown).

Because cocaine competes with reuptake of catecholamines in adrenergic neurons and a direct interaction of $S(-)$ cocaine with the alanine transporter was suggested by Dicke et al. (1993), the potency of $\mathrm{S}(+)$ adrenaline, $\mathrm{S}(-)$ adrenaline and $\mathrm{S}(+/-)$ noradrenaline to interfere with alanine uptake into our SMMV was also evaluated. Uptake of alanine at $15 \mathrm{sec}$ was not influenced by either of the compounds, namely, $99 \pm 17$, $97 \pm 13$, and $93 \pm 4 \%$ (mean $\pm \mathrm{SD}, n=4$ ) of representative control uptake, respectively.

Initial uptake of $250-\mu \mathrm{mol}\left[{ }^{3} \mathrm{H}\right]$-choline per liter in the presence of an outwardly directed choline gradient (trans-stimulation conditions) was significantly inhibited by several cationic drugs, as is shown in Table 4 . 

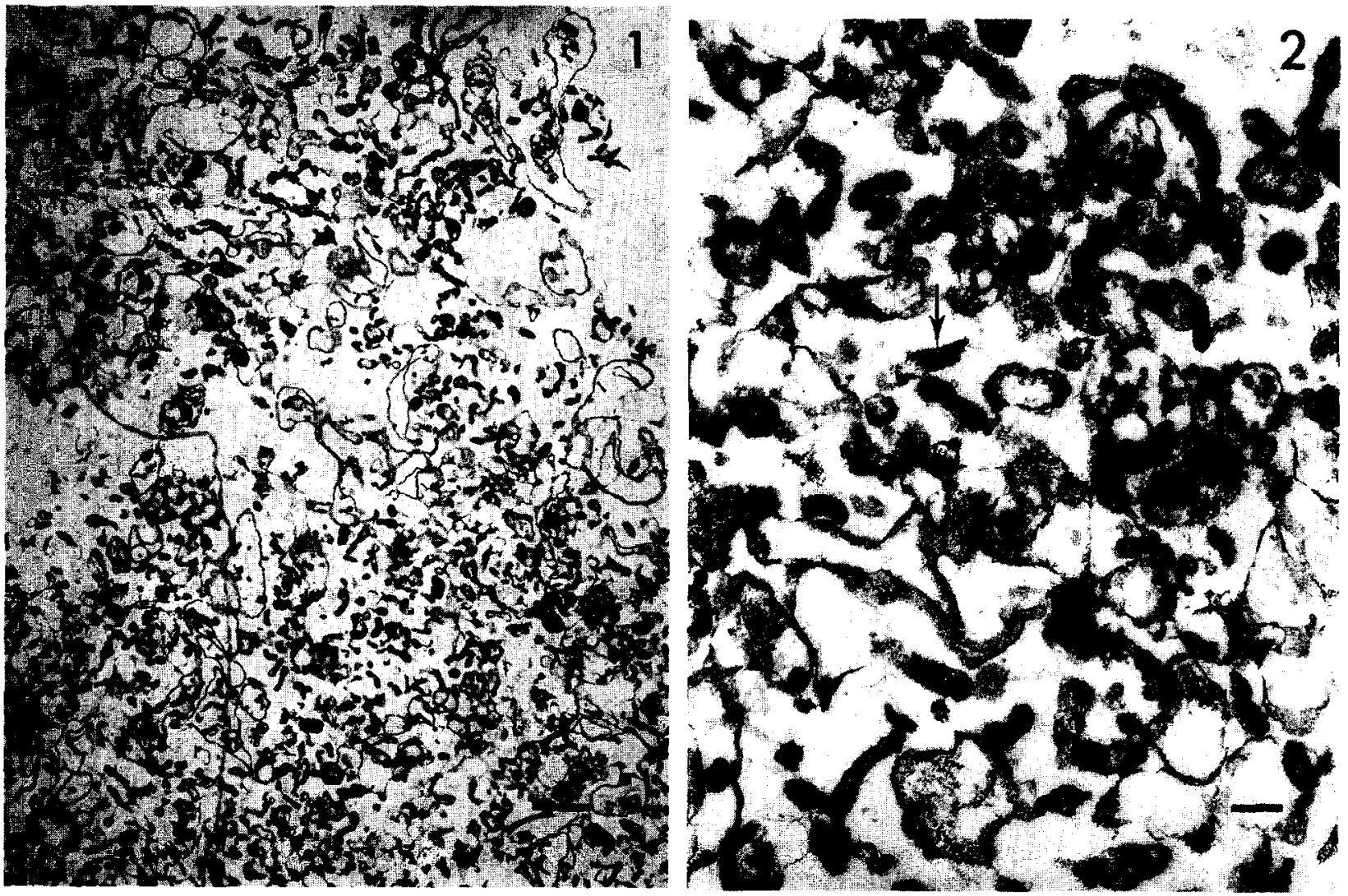

Figure 1. Electron micrographs of SMMV. At low magnification (16,000×, bar represents $1 \mu \mathrm{m})$ the membrane preparation appeared to be homogenous, vesicular, and free of subcellular organelles (1). At high magnification (40,000×, bar represents 200 $\mathrm{nm}$ ), fragments of microvilli are visible, and the microfilaments can be clearly distinguished (arrow) (2).

\section{Discussion}

In this report we describe the marker enzyme and transport characteristics of SMMV from human term placenta isolated according to an established, but slightly modified, method. The SMMV were used to investigate drug-nutrient interactions of several commonly used drugs with the alanine and choline transporter.

SMMV were isolated according to a procedure originally described for the isolation of rabbit renal brushborder membrane vesicles (Booth and Kenny, 1974), but proven to be useful also for the isolation of human placental SMMV (Glazier et al., 1988). However, to improve the isolation results, we decided to replace the homogenization step of placental tissue by mincing the tissue in a Waring blender to pieces of approximately 5 $\mathrm{mm}^{3}$. Then the mince was stirred for 30 min to loosen the microvilli and filtered through gauze to remove large tissue parts, after which the procedure according to Glazier et al. (1988) was continued. These modifications doubled the protein recovery $(0.6 \%$ to $1.2 \%)$ and increased alkaline phosphatase enrichment slightly (18fold to 22-fold). Apparent contamination of basal membranes in our SMMV was in the same range (5-fold enrichment in $\mathrm{Na}^{+} / \mathrm{K}^{+}$ATP-ase in our vesicles as compared to 6-fold enrichment in ouabaine binding in theirs). Although it is questioned in literature whether ATP-ases actually are located at the basal side of the human placenta exclusively (Eaton and Oakey, 1994), our modifications did not result in a higher contamination of ATP-ase-containing structures. Contamination of subcellular organelles possibly interfering in transport studies, as mitochondria and endoplasmatic reticulum, was very small. Functional contamination of basal membranes is assumed to be negligible because no significant intravesicular accumulation of free $\mathrm{Ca}^{2+}$ in the presence of ATP could be determined. This effect was shown in BMV (Fisher et al., 1987; Lafond et al., 1991) and not in SMMV (Brunette and Leclerc, 1991; Page et al., 1993), providing evidence for the location of an ATP-dependent $\mathrm{Ca}^{2+}$-transporter at the basal side in human placenta. However, Treinen and Kulkarni (1987) found ATP-stimulated uptake into SMMV. They concluded that this uptake might be into inside-out vesicles. Lafond et al. (1991) proposed that this effect might be a result of $\mathrm{Ca}^{2+}$-stimulated alkaline phosphatase activity in SMMV. These factors might also be of influence in the 


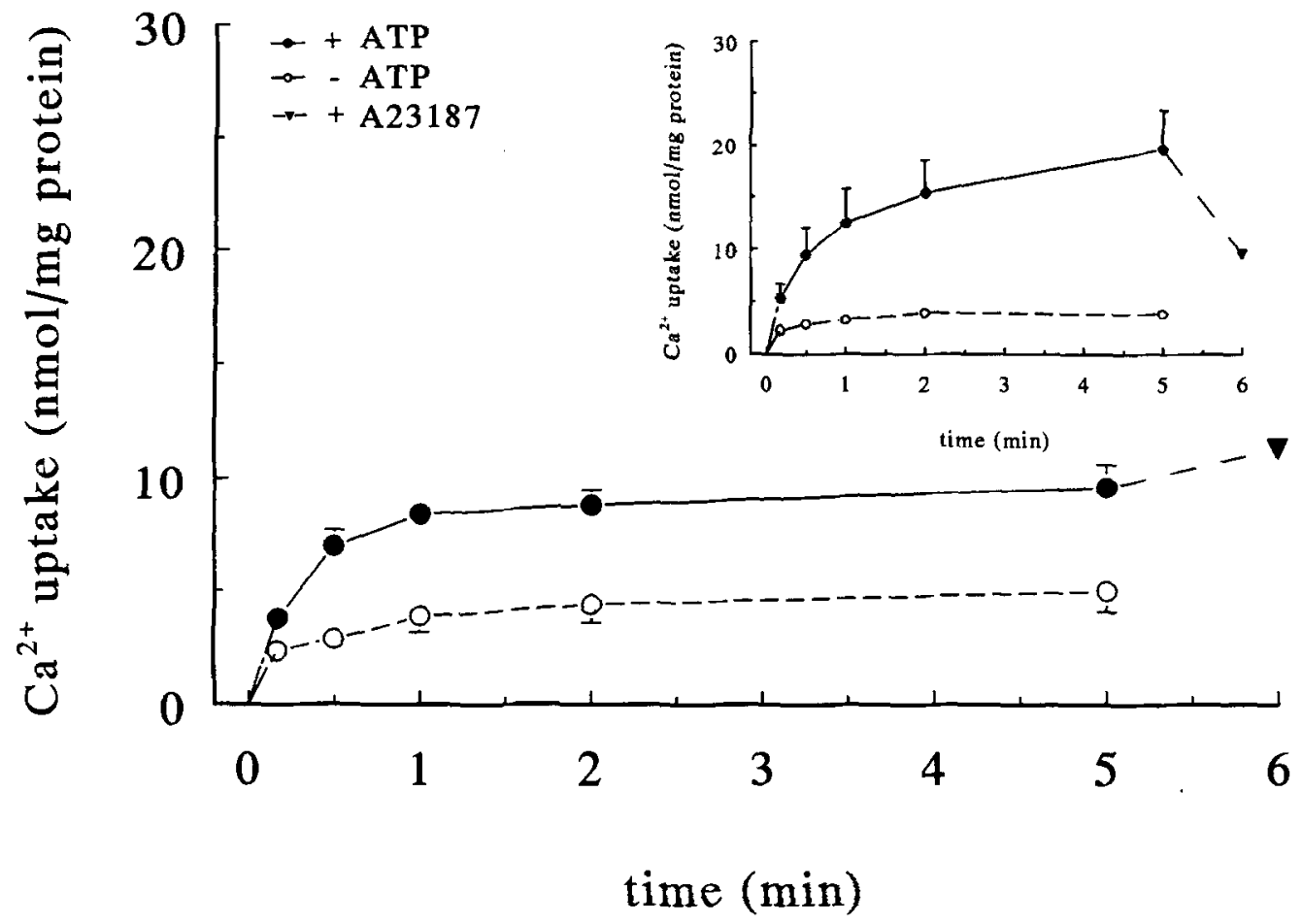

Figure 2. Effect of ATP and A23187 on the uptake of ${ }^{45} \mathrm{Ca}^{2+}$ into SMMV. Concentration of free $\mathrm{Ca}^{2+}$ was $1 \mu \mathrm{mol} / \mathrm{L}$, free $\mathrm{Mg}^{2+}$ $1.5 \mathrm{mmol} / \mathrm{L}$, ATP $3 \mathrm{mmol} / \mathrm{L}$, and A23187 $10 \mu \mathrm{g} / \mathrm{mL}$. Vesicles were suspended in 100-mmol mannitol per liter, $100-\mathrm{mmol} \mathrm{KCl}$ per liter, and 10-mmol Hepes-Tris per liter, $\mathrm{pH}=7.4$. Composition of the extravesicular media are described in Materials and Methods. Data are presented as nmol $/ \mathrm{mg}$ protein (mean $\pm \mathrm{SE} ; n=3$ ). Inset curve: Effect of ATP and A23187 on the uptake of ${ }^{45} \mathrm{Ca}^{2+}$ into BMV. Conditions were the same as described for SMMV.

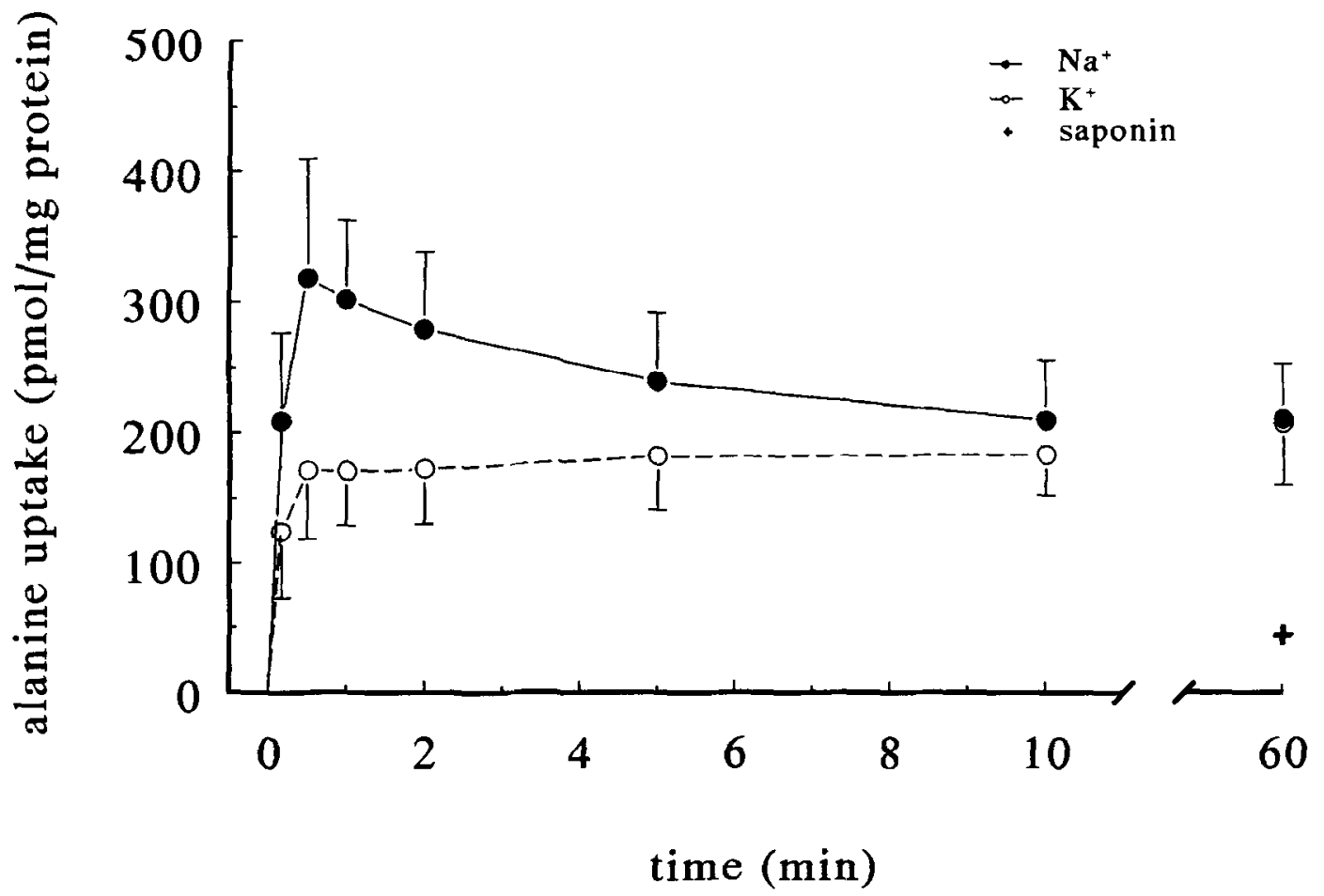

Figure 3. Time-dependent uptake of $100-\mu \mathrm{mol}\left[{ }^{3} \mathrm{H}\right]$-alanine per liter into SMMV in the presence and absence of an inwardly directed $\mathrm{Na}^{+}$-gradient. SMMV were suspended in 300-mmol mannitol per liter and 10-mmol Hepes-Tris per liter, $\mathrm{pH}=7.4$. Extravesicular media consisted of 50-mmol NaCl per liter or $50-\mathrm{mmol} \mathrm{KCl}$ per liter, 200-mmol mannitol per liter, and 10-mmol Hepes-Tris per liter, $\mathrm{pH}=7.4$. Data are presented as $\mathrm{pmol} / \mathrm{mg}$ protein (mean $\pm \mathrm{SD} ; n=10$ ). 


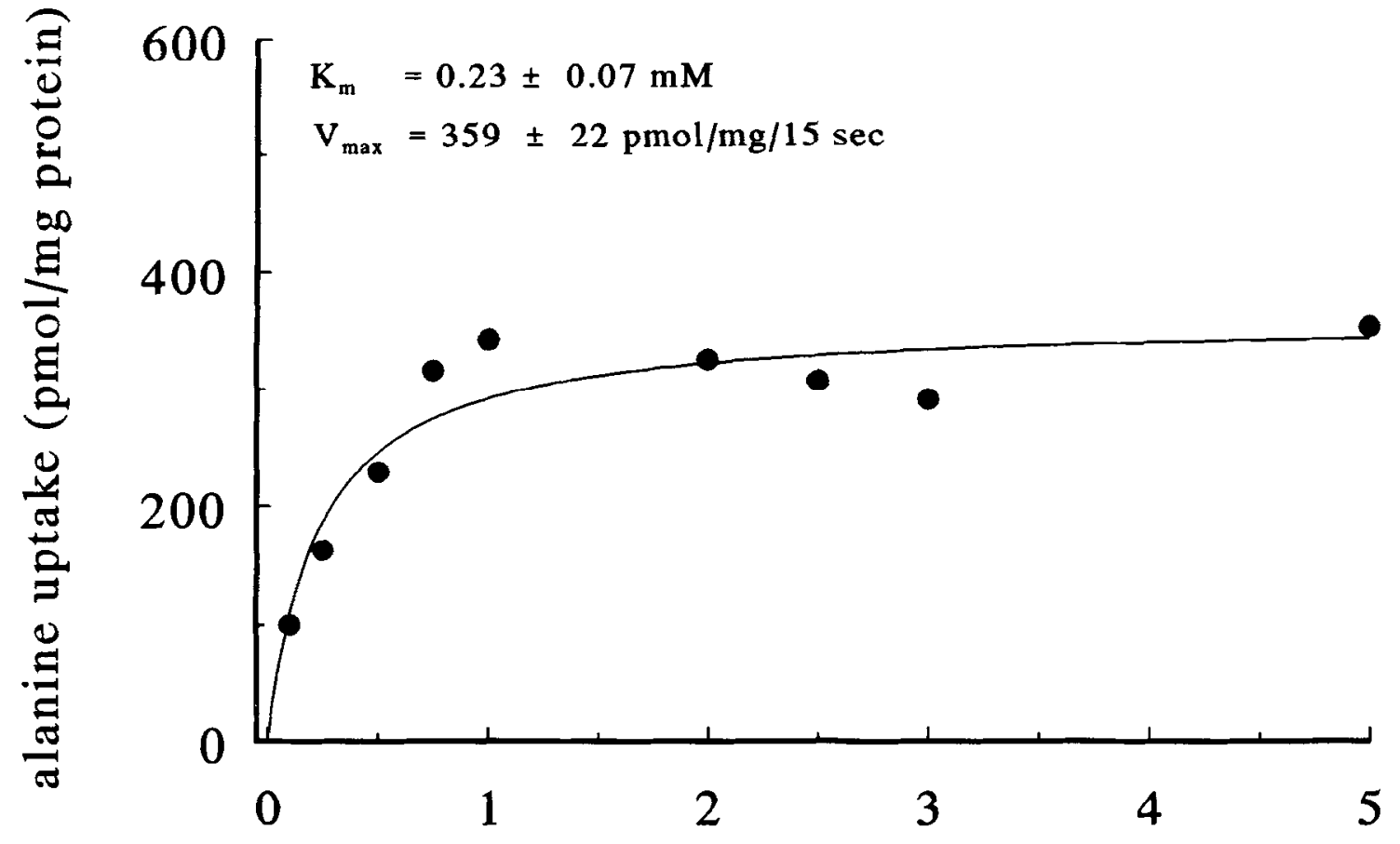

\section{concentration (mM)}

Figure 4. Concentration-dependent uptake of $\left.{ }^{3} \mathrm{H}\right]$-alanine at $15 \mathrm{sec}$ into SMMV. The curve represents the difference between uptake in the presence of an inwardly directed $\mathrm{Na}^{+}$- and $\mathrm{K}^{+}$-gradient. Vesicles were suspended in 300-mmol mannitol per liter and 10-mmol Hepes-Tris per liter, $\mathrm{pH}=7.4$. Extravesicular media consisted of 50-mmol $\mathrm{NaCl}$ per liter or 50-mmol $\mathrm{KCl}$ per liter and $10-\mathrm{mmol}$ Hepes-Tris per liter, $\mathrm{pH}=7.4$ and $0.1-5-\mathrm{mmol}$ alanine per liter adjusted to 310 mosmol with mannitol. Data are presented as $\mathrm{pmol} / \mathrm{mg}$ protein (mean; $n=2$ ).

small ATP-stimulated intravesicular $\mathrm{Ca}^{2+}$ uptake observed in our SMMV. We conclude that our SMMV are suitable for drug-nutrient interaction studies because alanine uptake was comparable to literature: sodiumcoupled, inhibitable by structural analogues, and saturable with kinetic parameters comparable to those reported by Johnson and Smith (1988) and Asai et al. (1982), $\mathrm{K}_{\mathrm{m}}=0.39$ and $0.38 \mathrm{mmol}$ per liter, respectively. The degree of inhibition of alanine uptake in the presence of a sodium gradient was the same as observed by Johnson and Smith (1988) and Enders et al. (1976). Obviously, the contribution of system $L$ exceeded the contribution of system A in total alanine transport. As was proposed by Asai et al. (1982), alanine transfer is mediated by system A (inhibitable with glycine) with high affinity and by system L (inhibitable with phenylalanine) with low affinity. System ASC, another alanine transporting system, is assumed to be located in cell membranes other than SMM, for example, BM (Johnson and Smith, 1988).

Three groups of commonly used drugs during pregnancy were investigated for their potency to interact with alanine transport. Organic anions, as analgesics and the diuretic furosemide, did not inhibit alanine uptake, whereas they did inhibit p-aminohippurate uptake in SMMV (van der Aa et al., 1994a). It seems that the amino acid transport systems $\mathrm{A}$ and $\mathrm{L}$ are insensitive to anionic drugs. The cationic $\mathrm{H}_{2}$-receptor antagonists had no influence on alanine transfer either. However, various cationic drugs were able to inhibit active uptake of the essential cationic nutrient choline. Inhibitor concentrations used were very high; consequently, no conclusions can be drawn yet on the possible clinical implications of the observed inhibition of choline transfer. The drugs of abuse ethanol and nicotine did not impair AIB transport in human placental perfused cotyledon and microvillus vesicles (Schenker et al., 1989a, 1989b). No inhibition of alanine transport was observed in our vesicles in the presence of high concentrations of nicotine, its metabolite cotinine, and ethanol. Thus, also in our study no evidence was found that fetal growth retardation after extensive ethanol consumption or nicotine exposition is related to a direct effect on amino acid membrane transport. Uptake of several amino 
Table 2. Effect of Amino Acids on Alanine Uptake into SMMV

\begin{tabular}{lcccc}
\hline Inhibitor & $\mathrm{mmol} / \mathrm{L}$ & $15 \mathrm{sec}$ & $60 \mathrm{sec}$ & $60 \mathrm{~min}$ \\
\hline Control & & $170 \pm 60$ & $220 \pm 70$ & $160 \pm 40$ \\
Glycine & 5 & $110 \pm 40^{*}$ & $145 \pm 16$ & $190 \pm 30$ \\
Phenylalanine & 5 & $80 \pm 30^{*}$ & $140 \pm 50$ & $180 \pm 30$ \\
\hline
\end{tabular}

Uptake of $100-\mu \mathrm{mol}\left[{ }^{3} \mathrm{H}\right]$-alanine per liter into SMMV in the presence of an inwardly directed sodium gradient. Vesicles were suspended in 300-mmol mannitol per liter and 10-mmol Hepes-Tris per liter, $\mathrm{pH}=7.4$. Extravesicular media consisted of $50-\mathrm{mmol} \mathrm{NaCl}$ per liter, 5-mmol inhibitor per liter, 10-mmol Hepes per liter adjusted to $\mathrm{pH}=7.4$ with Tris and to 310 mosmol with mannitol. Data are presented as $\mathrm{pmol} / \mathrm{mg}$ protein or percentage of control uptake (mean $\pm \mathrm{SD}, n=4) .{ }^{*} p<.05$.

Table 3. Effect of Several Drugs on Alanine Uptake into SMMV

\begin{tabular}{lccc}
\hline Inhibitor & $\mathrm{mmol} / \mathrm{L}$ & $\%$ control uptakc & $n$ \\
\hline None & & 100 & \\
Anionic drugs & & & \\
$\quad$ Probenecid & 5 & $102 \pm 16$ & 4 \\
Acetylsalicylic acid & 5 & $102 \pm 8$ & 4 \\
$\quad$ Sodium salicylate & 5 & $104 \pm 7$ & 4 \\
$\quad$ Indomethacin & 5 & $60 \pm 12^{*}$ & 4 \\
Furosemide & 5 & $87 \pm 13$ & 4 \\
$\quad$ Valproate & 5 & $99 \pm 15$ & 4 \\
Cationic drugs & & & \\
$\quad$ Cimetidine & 5 & $98 \pm 11$ & 4 \\
$\quad$ Famotidine & 5 & $94 \pm 5$ & 3 \\
Drugs of abuse & & $103 \pm 11$ & 3 \\
$\quad$ Cocaine & 1 & $107 \pm 4$ & 3 \\
$\quad$ Nicotine & 1 & $99 \pm 10$ & 3 \\
Cotinine & 1 & & \\
Ethanol & $87(0.4 \%)$ & $15 \% \mathrm{in}$ & \\
\hline
\end{tabular}

Uptake of $100-\mu$ mol $\left[{ }^{3} \mathrm{H}\right]$-alanine per liter at $15 \mathrm{sec}$ into SMMV in the presence of an inwardly directed sodium gradient. Vesicles were suspended in 300-mmol mannitol per liter and 10-mmol Hepes-Tris per liter, $\mathrm{pH}=7.4$. Extravesicular media consisted of $50-\mathrm{mmol} \mathrm{NaCl}$ per liter, inhibitor at the specified concentration, 10-mmol Hepes per liter adjusted to $\mathrm{pH}=7.4$ with Tris and to 310 mosmol with mannitol. Data are presented as percentage of representative control uptake (mean $\pm \mathrm{SD}$ ). Mean control uptake was $208 \pm 71 \mathrm{pmol} / \mathrm{mg}$ protein (mean $\pm \mathrm{SD} ; n=9$ ). ${ }^{*} p<.05$.

acids, however, was decreased in human placental villi in the presence of high concentrations of morphine, nicotine, and cocaine, but it was not clear whether the interaction was due to competition for the amino acid carriers (Barnwell and Rama Sastry, 1983). A more complex relationship was assumed between these drugs, $\mathrm{Ca}^{2+}$-fluxes, cholinergic system, and amino acid transport (Sastry et al., 1977, 1984). In this respect the report by Dicke et al. (1993), who observed stereoselective inhibition of sodium-dependent alanine uptake into human placental SMMV in the presence of low doses
Table 4. Effect of Cationic Drugs on Choline Uptake into SMMV

\begin{tabular}{lcc}
\hline Inhibitor & $\mathrm{mmol} / \mathrm{L}$ & $\%$ control uptake \\
\hline None & & 100 \\
Hemicholinium-3 & 5 & $15 \pm 5^{*}$ \\
Atropine & 5 & $22 \pm 8^{*}$ \\
Cimetidine & 5 & $46 \pm 4^{*}$ \\
Ranitidine & 5 & $48 \pm 7^{*}$ \\
Propranolol & 5 & $66 \pm 14^{*}$ \\
Procainamide & 5 & $72 \pm 9^{*}$ \\
\hline
\end{tabular}

Uptake of $250-\mu \mathrm{mol}\left[{ }^{3} \mathrm{H}\right]$-choline per liter at $10 \mathrm{sec}$ into SMMV in the presence of an outwardly directed choline gradient. Vesicles, suspended in 100-mmol mannitol per liter, $100-\mathrm{mmol} \mathrm{KCl}$ per liter, and $10-\mathrm{mmol}$ Hepes-Tris per liter, $\mathrm{pH}=7.4$, were pre-equilibrated with 5 -mmol unlabeled choline per liter and $20-\mu$ mol valinomycin per liter at $37^{\circ} \mathrm{C}$. Extravesicular media consisted of $100-\mathrm{mmol}$ mannitol per liter, $100-\mathrm{mmol} \mathrm{KCl}$ per liter, $20-\mu \mathrm{mol}$ valinomycin per liter, $10-\mathrm{mmol}$ Hepes-Tris per liter, $\mathrm{pH}=7.4,5-\mathrm{mmol}$ inhibitor per liter and unlabeled choline to achieve an extravesicular concentration of 250 $\mu \mathrm{mol} / \mathrm{L}$. Data are presented as percentage of representative control uptake (mean $\pm \mathrm{SD}, n=3$ or 4). Mean control uptake was $5003 \pm 498$ $\mathrm{pmol} / \mathrm{mg}$ protein (mean $\pm \mathrm{SD}, n=4$ ). ${ }^{*} p<.05$.

S(-)cocaine, is of special interest. Their results suggest a direct interaction of $\mathrm{S}(-)$ cocaine with the alanine transporter and are in contrast with our observations, where no inhibition was found in the presence of cocaine, $\mathrm{S}(+)$ - and $\mathrm{S}(-)$ adrenaline and $\mathrm{S}(+/-)$ noradrenaline. However, the inhibition they observed was low, and it is questionable whether uptake at $1 \mathrm{~min}$ in their experiments can be considered as a true measure of initial transport rate, because uptake at $30 \mathrm{sec}$ or later clearly deviated from linearity in our experiments (Figure 3). Another difference is that our control uptake at $15 \mathrm{sec}$ was about 3000 times higher than their uptake at $1 \mathrm{~min}$. Probably the sensitivity of the alanine transporter to exogenous compounds is higher at low alanine concentrations. Because maternal plasma contains a relatively high concentration of alanine $(0.25 \mu \mathrm{mol} / \mathrm{mL}$; Philipps et al., 1978), low alanine concentrations are not likely to occur in vivo. Even when a cocaine-addicted mother is underfed, fetal growth retardation would be merely a result of malnutrition itself rather than a result of an interaction of cocaine with amino acid transport.

In conclusion, our SMMV showed marker enzyme, microscopic, and functional characteristics in accordance with literature. Uptake of alanine, the most abundant amino acid in maternal plasma, was sodiumdependent, saturable, and inhibitable by structural analogues. Commonly used drugs, like analgesics, $\mathrm{H}_{2}$-receptor antagonists and drugs of abuse did not interact with alanine transport, whereas several cationic drugs inhibited choline uptake. The membrane vesicles isolated and used in this study provide a suitable tool for screening the inhibitory potency of drugs on nutrient transporters. 
This work was supported by the Netherlands Organization for Scientific Research (NWO). Wc gratcfully acknowledge Dr. R. J. M. Bindels of the Department of Cell Physiology, University of Nijmegen, for his assistance in the $\mathrm{Ca}^{2+}$ experiments, Miss J. Pertijs of the Department of Toxicology, University of Nijmegen, for preparing the electron micrographs and Miss E. Katzma for her skillful technical assistance. We are indebted to the Department of Gynaecology and Obstetrics, University Hospital St. Radboud Nijmegen, for their assistance in obtaining placentae.

\section{References}

Asai M, Keino H, Kashiwamata S (1982) L-Alanine uptake by microvillous brush border membrane vesicles prepared from human placenta. Biochem Int 4:377-384

Asai M, Narita O, Kashiwamata S (1984) Effects of acetaldehyde and/or ethanol on neutral amino acid transport systems in microvillous brush border membrane vesicles prepared from human placenta. Experientia 4:1566-1568.

Barnwell SL, Rama Sastry BV (1983) Depression of amino acid uptake in human placental villus by cocaine, morphine and nicotine. Troph Res 1:101-120.

Booth, AG, Kenny AJ (1974) A rapid method for the preparation of microvilli from rabbit kidney. Biochem J 142:575-581.

Booth AG, Olaniyan RO, Vanderpuye OA (1980) An improved method for the preparation of human placental syncytiotrophoblast microvilli. Placenta 1:327-336.

Boyd CAR, Lund EK (1981) L-Proline transport by brush border membrane vesicles prepared from human term placenta. $J$ Physiol 315:9-19.

Brunette MG, Leclerc M (1991) $\mathrm{Ca}^{2+}$ transport through the brush border membrane of human placenta syncytiotrophoblasts. Can $J$ Physiol Pharmacol 70:835-842.

Dicke JM, Verges DK, Polakoski KL (1993) Cocaine inhibits alanine uptake by human placental microvillous membrane vesicles. $A m J$ Ohstet Gynecol 169:515-521.

Eaton BM, Oakey MP (1994) Sequential preparation of highly purified microvillous and basal syncytiotrophoblast membranes in substantial yield from a single term placenta: Inhibition of microvillous alkaline phosphatase activity by EDTA. Biochim Biophys Acto 1193:85-92.

Enders RH, Judd M, Donohue TM, Smith CH (1976) Placental amino acid uptake. III. Transport systems for neutral amino acids. $A m J$ Physiol 230:706-710.

Fant ME, Harbison RD (1981) Syncytiotrophoblast membrane vesicles: A model for examining the human placental cholinergic system. Teratology 24:187-199.

Fisher GJ, Kelley LK, Smith CH (1987) ATP-dependent calcium transport across basal plasma membranes of human placental trophoblast. Am J Physiol 252:C38-C46.

Ghijsen WEJM, de Jong MD, van Os CH (1982) ATP-dependent calcium transport and its correlation with $\mathrm{Ca}^{2+}$-ATPase activity in basolateral plasma membranes of rat duodenum. Biochim Biophys Acta 689:85-94.

Glazier JD, Jones CJP, Sibley CP (1988) Purification and $\mathrm{Na}^{+}$uptake by human placental microvillus membrane vesicles prepared by three different methods. Biochim Biophys Acta 945:127-134.

Hoeltzli SD, Kelley LK, Moe AJ, Smith CH (1990) Anionic amino acid transport systems in isolated basal plasma membrane of human placenta. Am J Physiol 259:C47-C55.

Illsley NP, Wang Z-Q, Gray A, Sellers MC, Jacobs MM (1990) Simultaneous preparation of paired, syncytial, microvillous and basal membranes of human placenta. Biochim Biophys Acta 1029: $218-226$.
Johnson LW, Smith CH (1988) Neutral amino acid transport systems of microvillous membrane of human placenta. Am J Physiol 254: C773-C780.

Kelley LK, Smith CH, King BF (1983) Isolation and partial characterization of the basal cell membrane of human placental trophoblast. Biochim Biophys Acta 734:91-98.

Kihlstrom I, Kihlstrom JE (1981) An improved method for perfusion of the guinea pig placenta in situ giving viable condition demonstrated by placental transport of amino acids ( $\mathrm{L}$ - and D-alanine). Biol Neonate 39:150-159.

Lafond J, Leclerc M, Brunette MG (1991) Characterization of calcium transport by basal plasma membranes from human placental syncytiotrophoblast. J Cell Physiol 148:17-23.

Metzler CM, Weiner DL (1989) PCNONLIN (3.0) Software for statistical analysis of nonlinear models on micros. I exington, $\mathrm{KY}$, USA: SCI Software.

Mircheff AK, Wright EM (1976) Analytical isolation of plasma membranes of intestinal epithelial cells. Identification of $\mathrm{Na}^{+} / \mathrm{K}^{+}$ ATP-ase rich membranes and the distribution of enzyme activities. $J$ Membr Biol 28:309-333.

Omura, T, Takesue S (1970) A new method for simultaneous purification of cytochrome $B_{5}$ and NADPH-cytochrome $C$ reductase from rat liver microsomes. $J$ Biochem 67:249-257.

Page KR (1993) The Physiology of the Human Placenta. King's Lynn and Guilford, England: Biddles Ltd.

Page KR, Abramovich DR, Bush P, Clarke S, Dacke CG, Pereira J, Willoughby D (1993) ATP action on calcium uptake by human placental microvillous border vesicles. J Physiol 459:495P.

Pennington RJ (1961) Biochemistry of dystrophic muscle: Mitochondrial succinate-tetrazolium reductase and adenosine triphosphatase. Biochem $J$ 80:649-654.

Philipps AF, Holzman IR, Teng C, Battaglia FC (1978) Tissue concentrations of free amino acids in term human placentas. Am $J$ Obstet Gynecol 15:881-887.

Rowell PP, Rama Sastry BV (1981) Human placental cholinergic system: Depression of the uptake of $\alpha$-aminoisobutyric acid in isolated human placental villi by choline acetyltransferase inhibitors. J Pharmacol Exp Ther 216:232-238.

Russel FGM, van der Linden PEM, Vermeulen WG, Heijn M, van Os $\mathrm{CH}$, van Ginneken CAM (1988) $\mathrm{Na}^{+}$and $\mathrm{H}^{+}$gradient-dependent transport of p-aminohippurate in membrane vesicles from dog kidney cortex. Biochem Pharmacol 37:2639-2649.

Rybakowski C, Gnepel E, Leichtweiss, Schröder H (1993) Acetylsalicylic acid inhibits the uptake of L-alanine into the trophoblast of the guinea pig placenta. Naunyn Schmiedebergs Arch Pharmacol 347(suppl):R73/257.

Sastry BVR, Barnwell SL, Moore RD (1984) Factors affecting the uptake of $\alpha$-amino acids by human placental villus: Acetylcholine, phospholipid methylation, $\mathrm{Ca}^{2+}$, and cytoskeletal organization. Troph Res 1:81-100.

Sastry BVR, Olubadewo J, Boehm F (1977) Effccts of nicotine and cocaine on the release of acetylcholine from isolated human placental villi. Arch Int Pharmacodyn Ther 229:23-36.

Schenker S, Dicke J, Johnson RF, Hays SE, Henderson GI (1989a) Effect of ethanol on human placental transport of model amino acids and glucose. Alcoholism Clin Exp Res 13:112-119.

Schenker S, Johnson RF, Hays SE, Ganeshappa R, Henderson GI (1989b) Effects of nicotine and nicotine/ethanol on human placental amino acid transfer. Alcohol 6:289-296.

Schoot BM, Schoots AF, de Pont JJHHM, Schuurmans-Stekhoven FMAH, Bonting SL (1977) Studies on (Na-K) activated ATP-ase: Effects of N-ethylmaleimide on overall and partial reactions. Biochim Biophys Acta 483:181-192.

Scpulveda FV, Wooding FBP (1984) Net transfer of L-alanine across sheep and goat placental chorionic epithelium in vitro. $J$ Physiol 358:111P. 
Smith NC, Brush MG, Luckett S (1974) Preparation of human placental villous surface membrane. Nature 252:302-303.

Treinen KA, Kulkarni AP (1987) ATP-dependent $\mathrm{Ca}^{2+}$ uptake in brush border membranes of human term placenta. Placenta 8:477486.

van der Aa EM, Meuwsen IJB, Boersen ACM, Wouterse AC, Copius Peereboom-Stegeman JHJ, Russel FGM (1994a) p-Aminohippurate uptake by syncytial microvillous membrane vesicles of human term placenta. Placenta 15:279-289.

van der Aa EM, Wouterse AC, Copius Peereboon-Stegeman JHJ, Russel FGM (1994b) Uptake of choline into syncytial microvillus membrane vesicles of human term placenta. Biochem Pharmacol 47:453-456.

van Heeswijk MPE, Geertsen JAM, van Os CH (1984) Kinetic properties of the ATP-dependent $\mathrm{Ca}^{2+}$ pump and the $\mathrm{Na}^{+} / \mathrm{Ca}^{2+}$ exchange system in basolaleral membranes from rat kidney cortex. J Membr Biol 79:19-31.

Welsch F (1978) Choline metabolism in human term placenta: Studies on de novo synthesis and the effect on the metabolic fate of [N-Me- $\left.{ }^{3} \mathrm{H}\right]$-choline. Biochem Pharmacol 27:1251-1257.

Yudilevich DL, Sweiry JH (1985) Transport of amino acids in the placenta. Biochim Biophys Acta 822:169-201. 